BMJ Open

Diabetes

Research

\& Care

\title{
Glucose metabolism among obese and non-obese children of mothers with gestational diabetes
}

Jun Lu, ${ }^{1,2}$ Yuying Gu, ${ }^{2,3}$ Leishen Wang, ${ }^{4}$ Weiqin Li, ${ }^{4}$ Shuang Zhang, ${ }^{4}$ Huikun Liu, ${ }^{4}$ Junhong Leng (1) , Jin Liu, ${ }^{4}$ Shuo Wang, ${ }^{4}$ Andrea A Baccarelli, ${ }^{5}$ Lifang Hou, ${ }^{6}$ Gang $\mathrm{Hu}$ (1) ${ }^{2}$

\section{ABSTRACT}

To cite: Lu J, Gu Y, Wang L, et al. Glucose metabolism among obese and nonobese children of mothers with gestational diabetes. BMJ Open Diab Res Care 2020;8:e000822. doi:10.1136/ bmjdrc-2019-000822

Received 13 August 2019 Revised 9 February 2020 Accepted 14 February 2020

\section{Check for updates}

\section{(c) Author(s) (or their} employer(s)) 2020. Re-use permitted under CC BY-NC. No commercial re-use. See rights and permissions. Published by BMJ.

For numbered affiliations see end of article.

Correspondence to

Dr Gang Hu; gang.hu@pbrc.edu
Objectives Abdominal obesity is more closely associated with diabetes than general obesity in adults, however, it is unknown which kind of obesity is more closely associated with abnormal glucose metabolism in children.

Research design and methods We recruited 973 children (aged 3.08 \pm 1.06 ) of mothers with prior gestational diabetes mellitus (GDM). Children's height, weight, waist circumstance, fasting glucose and insulin were measured using standardized methods. Logistic regression models were used to assess the single and joint associations of general and abdominal obesity with the risks of hyperglycemia (the upper quartile of fasting glucose), insulin resistance (the upper quartile of homeostatic model assessment of insulin resistance (HOMA-IR)), and $\beta$-cell dysfunction (the lower quartile of HOMA- $\% \beta$ ).

Results Compared with normal weight children, children with general overweight/obesity had higher levels of HOMA-IR and HOMA- $\% \beta$, higher ORs for hyperglycemia $(1.56,95 \% \mathrm{Cl} 1.06$ to 2.30$)$ and insulin resistance (3.44, $95 \% \mathrm{Cl} 2.32$ to 5.09$)$, but a lower OR for $\beta$-cell dysfunction $(0.65,95 \% \mathrm{Cl} 0.41$ to 1.04$)$. Children with abdominal obesity had an increased risk of insulin resistance (2.54, $95 \% \mathrm{Cl} 1.71$ to 3.76 ) but not hyperglycemia and $\beta$-cell dysfunction compared with children with normal waist circumstance. In the joint analyses, general overweight children with and without abdominal obesity had an increased risk of hyperglycemia and insulin resistance compared with normal weight children.

Conclusions General obesity was more closely associated with abnormal glucose metabolism than abdominal obesity in children of mothers with GDM.

\section{INTRODUCTION}

The Global Burden of Disease 2015 Obesity Group reported that the prevalence and burden of childhood obesity has increased greatly worldwide from 1980 to 2017 . $^{1}$ Similar trend has been observed in China, and the prevalence of obesity among children aged 6-11 years has reached 13.2\% in 2015. ${ }^{23}$ Prospective studies showed that overweight and obesity during childhood are major risk factors for adulthood obesity and cardiometabolic diseases such as type

\section{Significance of this study}

What is already known about this subject?

- Obesity was associated with childhood insulin resistance, and abdominal obesity was more closely associated with type 2 diabetes than general obesity in adults. It is unknown which kind of obesity is more closely associated with abnormal glucose metabolism in children.

What are the new findings?

- Both general and abdominal obesity were associated with children's insulin resistance, but only general obesity was associated with hyperglycemia in children of mothers with gestational diabetes mellitus. General obesity was more closely associated with abnormal glucose metabolism than abdominal obesity.

How might these results change the focus of research or clinical practice?

- Longitudinal studies are warranted to investigate long-term effects of obesity and weight management on glucose metabolism in children.

2 diabetes, the metabolic syndrome, and cardiovascular diseases. ${ }^{4-6}$ Some studies also indicated that obesity was associated with increased risks of insulin resistance and type 2 diabetes in children. ${ }^{7-9}$ Several adiposity indicators have been reported to correlate with glucose metabolism in children. A UK study demonstrated that body mass index (BMI), waist circumference and skinfold thicknesses were positively associated with insulin resistance in all ethnic groups, and correlated with HbA1c levels in South Asian and black African-Caribbean children but not in white Europeans. ${ }^{7}$ Another US study reported that both fat mass and waist circumference positively correlated with insulin resistance among children. ${ }^{9}$ However, no studies have assessed the association of 
various anthropometric obesity indicators with glucose metabolism in Chinese children.

Some studies have found that offspring of mothers with gestational diabetes mellitus (GDM) were more vulnerable to obesity, insulin resistance and diabetes. ${ }^{1011}$ Therefore, it is urgent to investigate the association between adiposity and glucose metabolism in the offspring of mothers with GDM. In the present study, we investigated the effects of general and abdominal obesity on major glucose metabolic measures (hyperglycemia, insulin resistance, and $\beta$-cell dysfunction) in children of mothers with GDM in Tianjin, China.

\section{SUBJECTS AND METHODS}

\section{GDM screening process}

Tianjin is the fourth largest city in China, and there are about 4.3 million residents in six central districts. According to the WHO's criteria, an urban universal screening of GDM was launched in all six central districts in 1999. The screening rate was reported to be $>91 \%$ between 1999 and 2008. ${ }^{12}$ GDM was screened using a twostep method. All pregnant women (at their 26-30 gestational weeks) were first invited to participate in a 1-hour oral glucose tolerance test (OGTT) with $50 \mathrm{~g}$ glucose load in their community health centers. Those with glucose reading $\geq 7.8 \mathrm{mmol} / \mathrm{L}$ were referred to the Tianjin Women's and Children's Health Center to undergo a 2-hour OGTT with $75 \mathrm{~g}$ glucose load. The pregnant women were classified as having GDM if they met the WHO's criteria of diabetes (fasting glucose $\geq 7 \mathrm{mmol} / \mathrm{L}$ or 2-hour glucose $\geq 11.1 \mathrm{mmol} / \mathrm{L}$ ) or impaired glucose tolerance (IGT) (2-hour glucose $\geq 7.8$ and $<11.1 \mathrm{mmol} / \mathrm{L}^{13}$

\section{Study population}

Totally 76325 women were under screening of GDM from 2005 to 2009, and 4644 of them were diagnosed with GDM. All 4644 GDM women were invited to participate in the Tianjin Gestational Diabetes Mellitus Prevention Program. A total of 1263 GDM women and their children finished the baseline survey from August 2009 to July 2011. Of them, 973 children had measured fasting glucose and insulin and were included in the present analysis. No differences in 2-hour OGTT concentration, fasting glucose concentration, and the prevalence of IGT and diabetes at 26-30 gestational weeks were observed among women who participated in the postpartum survey and those who did not. ${ }^{14}$ Written informed consents were collected from all participants.

\section{Questionnaires and measurements}

We collected mothers' information by a self-administered questionnaire, including sociodemographic characteristics, such as age, marital status, education $(<13,13-16$, and $\geq 16$ years), family income ( $<¥ 5000 /$ month, $¥ 5000$ $¥ 8000 /$ month, and $\geq ¥ 8000 /$ month), and occupation; pregnancy outcomes (pre-pregnancy weight, weight gain during pregnancy, gestational age, and the number of births in the index pregnancy); and smoking status (non-smokers, former smokers, and current smokers). Women were classified as having a history of hypertensive disorder of pregnancy (HDP) if they reported doctordiagnosed hypertension after 20 weeks (including gestational hypertension, pre-eclampsia, severe pre-eclampsia or eclampsia) of gestation on the questionnaire. ${ }^{15} \mathrm{We}$ collected children's information by another questionnaire completed by their mothers, including children's general information, such as gender, birth date, birth weight, birth length, lactation (exclusive formula, mixed or exclusive breast feeding) and lactation duration; history of diseases and medication; dietary habits (using a validated food frequency questionnaire $(\mathrm{FFQ}))^{16}$; and routine activities (indoor and outdoor activities, screen time, and sleep duration). ${ }^{17}$

All children underwent a physical examination. Height and weight were measured while the participants were barefoot and in light indoor clothing by trained research doctors according to the standardized protocol. BMI was calculated as the weight divided by height squared $(\mathrm{kg} /$ $\mathrm{m}^{2}$ ). Waist circumference was measured mid-way between the lower rib margin and the iliac crest. All mothers' prepregnancy BMI was evaluated using their self-reported pre-pregnancy weight in kilos and their measured height in meters. Children's Z scores for BMI for age were calculated according to the WHO growth reference. ${ }^{18} 19$ Children's BMI was categorized as normal weight, BMI $<85$ th percentile; overweight, 85th percentile $\leq$ BMI $<95$ th percentile; and general obesity, BMI $\geq 95$ th percentile, according to the WHO age and gender-specific growth reference. ${ }^{18} 19$ Abdominal obesity was defined as a waist circumstance $\geq 90$ th percentile according to anthropometric reference data for children and adults in the USA, $2007-2010 .^{20}$

Blood samples were drawn from all children after an overnight fasting of at least 6 hours. Fasting plasma glucose was measured using an automatic analyzer (TBA-120FR; Toshiba, Japan), and insulin was measured with chemiluminescence using a Siemens ADVIA Centaur CP Immunoassay System. Homeostatic model assessment (HOMA) was used to estimate $\beta$-cell secretory function (HOMA$\% \beta$ ) and insulin resistance (HOMA-IR) as described previously. ${ }^{14} \beta$-cell dysfunction was defined as the lower quartile of HOMA-\% $\beta$. Insulin resistance and hyperglycemia were defined as the upper quartile of HOMA-IR and fasting glucose of total sample, respectively.

\section{Statistical analysis}

The general characteristics (continuous and categorical variables) of both mothers and children according to children's different statuses of general and abdominal obesity were performed using the $\chi^{2}$ test or general linear model. Logistic regression models were used to estimate ORs of childhood major abnormal glucose metabolism (hyperglycemia, insulin resistance, and $\beta$-cell dysfunction) according to different statuses of general and abdominal obesity. In the joint analyses, children were divided into four groups: normal weight and normal waist 
Table 1 Maternal and child characteristics according to children's general and abdominal obesity status

\begin{tabular}{|c|c|c|c|c|c|}
\hline & Normal weight & & General overw & besity & \\
\hline & $\begin{array}{l}\text { Normal waist } \\
\text { circumstance }\end{array}$ & Abdominal obesity & $\begin{array}{l}\text { Normal waist } \\
\text { circumstance }\end{array}$ & Abdominal obesity & $P$ value \\
\hline Subjects, $\mathrm{n}$ & 727 & 75 & 72 & 99 & \\
\hline Maternal characteristics & & & & & \\
\hline Age at delivery (years) & $31.0 \pm 3.45$ & $31.2 \pm 3.35$ & $30.9 \pm 3.80$ & $31.1 \pm 4.23$ & 0.93 \\
\hline Pre-pregnancy BMI (kg/m²) & $22.9 \pm 3.23$ & $22.5 \pm 3.24$ & $24.8 \pm 3.33$ & $24.2 \pm 3.42$ & $<0.001$ \\
\hline Gestational weight gain $(\mathrm{kg})$ & $16.4 \pm 5.78$ & $16.5 \pm 5.81$ & $18.3 \pm 6.82$ & $18.1 \pm 6.72$ & 0.005 \\
\hline Gestational age at delivery (weeks) & $39.1 \pm 1.51$ & $39.1 \pm 1.57$ & $38.7 \pm 1.34$ & $38.9 \pm 1.53$ & 0.13 \\
\hline Education (\%) & & & & & 0.21 \\
\hline$<13$ years & 21.0 & 21.3 & 25.0 & 29.3 & \\
\hline $13-16$ years & 71.5 & 62.7 & 72.2 & 66.7 & \\
\hline$\geq 16$ years & 7.4 & 16.0 & 2.8 & 4.0 & \\
\hline Smoking status (\%) & & & & & 0.19 \\
\hline Never & 96.3 & 97.3 & 91.7 & 92.9 & \\
\hline Past & 2.6 & 1.3 & 6.9 & 3.0 & \\
\hline Current & 1.1 & 1.3 & 1.4 & 4.0 & \\
\hline Offspring characteristics & & & & & \\
\hline Boy $(\%)$ & 51.3 & 60.0 & 55.6 & 65.7 & 0.006 \\
\hline Age (years) & $3.11 \pm 1.05$ & $2.48 \pm 0.70$ & $3.47 \pm 1.27$ & $3.00 \pm 0.96$ & $<0.001$ \\
\hline Birth weight (g) & $3497 \pm 508$ & $3649 \pm 558$ & $3743 \pm 543$ & $3638 \pm 527$ & $<0.001$ \\
\hline Mode of infant feeding (\%) & & & & & 0.59 \\
\hline Exclusive breast feeding & 44.6 & 36 & 33.3 & 47.5 & \\
\hline Exclusive formula feeding & 41.5 & 50.7 & 45.8 & 41.4 & \\
\hline Mixed feeding & 13.9 & 13.3 & 20.8 & 11.1 & \\
\hline Outdoor activity (hours/day) & $1.62 \pm 0.85$ & $1.80 \pm 0.88$ & $1.66 \pm 0.84$ & $1.69 \pm 0.96$ & 0.34 \\
\hline Screen time (hours/day) & $1.23 \pm 0.98$ & $1.32 \pm 1.12$ & $1.65 \pm 1.32$ & $1.51 \pm 1.07$ & 0.001 \\
\hline Sleeping time (\%) & & & & & 0.13 \\
\hline$\leq 8$ hours/day & 1.7 & 2.7 & 4.2 & 2.0 & \\
\hline 9-10 hours/day & 46.6 & 29.3 & 62.5 & 47.5 & \\
\hline$\geq 11$ hours/day & 51.7 & 68.0 & 33.3 & 50.5 & \\
\hline Dietary intake & & & & & \\
\hline Energy (kcal/day) & $883 \pm 231$ & $948 \pm 199$ & $946 \pm 244$ & $1037 \pm 288$ & $<0.001$ \\
\hline Protein (\% of energy) & $16.2 \pm 2.77$ & $16.8 \pm 3.09$ & $15.6 \pm 2.44$ & $17.0 \pm 3.14$ & 0.004 \\
\hline Fat (\% of energy) & $32.4 \pm 7.24$ & $33.2 \pm 7.15$ & $31.1 \pm 6.46$ & $31.0 \pm 7.76$ & 0.11 \\
\hline Carbohydrate (\%) & $52.9 \pm 7.58$ & $51.4 \pm 7.71$ & $54.7 \pm 7.16$ & $53.5 \pm 8.13$ & 0.06 \\
\hline Fiber (g/1000 kcal) & $3.94 \pm 1.02$ & $3.64 \pm 1.19$ & $3.85 \pm 0.92$ & $3.96 \pm 1.03$ & 0.10 \\
\hline Body mass index $\left(\mathrm{kg} / \mathrm{m}^{2}\right)$ & $15.2 \pm 0.93$ & $15.8 \pm 0.81$ & $17.7 \pm 0.74$ & $19.0 \pm 2.08$ & $<0.001$ \\
\hline BMI for age Z-score & $-0.26 \pm 0.73$ & $0.15 \pm 0.63$ & $1.52 \pm 0.41$ & $2.30 \pm 1.15$ & $<0.001$ \\
\hline Waist circumstance $(\mathrm{cm})$ & $49.5 \pm 3.11$ & $55.6 \pm 3.01$ & $53.8 \pm 4.02$ & $59.2 \pm 5.62$ & $<0.001$ \\
\hline Fasting glucose (mmol/L) & $4.35 \pm 0.36$ & $4.33 \pm 0.37$ & $4.47 \pm 0.36$ & $4.44 \pm 0.32$ & 0.007 \\
\hline Fasting insulin (mIU/L) & $2.44 \pm 1.64$ & $2.26 \pm 1.94$ & $3.29 \pm 1.74$ & $4.23 \pm 3.64$ & $<0.001$ \\
\hline
\end{tabular}

Overweight or obesity was defined as a body mass index $\geq 85$ th percentile according to the WHO age and gender-specific growth reference.

Abdominal obesity was defined as a waist circumstance $\geq 90$ th percentile according to anthropometric reference data for children and adults in the USA, 2007-2010.

BMI, body mass index.

circumstance, central obesity only, general obesity only, and general obesity concomitant with central obesity. All analyses were adjusted for children's sex, age, birth weight, and feeding status (model 1); and then children's lifestyles including outdoor physical activity time, screen time, sleep time, daily energy intake, daily fiber intake, energy from carbohydrate, protein, and fat based on FFQ (model 2); and further for maternal delivery age, smoking 
Table 2 Childhood major glucose metabolism outcomes according to general and abdominal obesity status

\begin{tabular}{|c|c|c|c|c|c|c|}
\hline & \multicolumn{2}{|c|}{ General obesity status } & \multirow[b]{2}{*}{$P$ value } & \multicolumn{2}{|c|}{ Abdominal obesity status } & \multirow[b]{2}{*}{$P$ value } \\
\hline & $\begin{array}{l}\text { Normal } \\
\text { weight }\end{array}$ & Overweight/obesity & & $\begin{array}{l}\text { Normal waist } \\
\text { circumstance }\end{array}$ & Abdominal obesity & \\
\hline Fasting glucose (mmol/L) & $4.35 \pm 0.01$ & $4.43 \pm 0.03$ & 0.008 & $4.36 \pm 0.01$ & $4.39 \pm 0.03$ & 0.28 \\
\hline Fasting insulin (mlU/L) & $2.44 \pm 0.07$ & $3.75 \pm 0.15$ & $<0.001$ & $2.49 \pm 0.07$ & $3.51 \pm 0.15$ & $<0.001$ \\
\hline \multicolumn{7}{|l|}{ Hyperglycemia } \\
\hline Cases, n (\%) & $182(22.7)$ & $60(35.1)$ & & $191(23.9)$ & $51(29.3)$ & \\
\hline \multicolumn{7}{|l|}{ OR (95\% Cl) } \\
\hline Model 1 & 1 & 1.74 (1.21 to 2.50$)$ & 0.003 & 1 & 1.33 (0.91 to 1.93$)$ & 0.14 \\
\hline Cases, n (\%) & $163(20.3)$ & 79 (46.2) & & $178(22.3)$ & $64(36.8)$ & \\
\hline \multicolumn{7}{|l|}{ OR (95\% Cl) } \\
\hline Model 1 & 1 & 3.68 (2.55 to 5.30$)$ & $<0.001$ & 1 & 2.75 (1.89 to 4.00$)$ & $<0.001$ \\
\hline Model 2 & 1 & 3.41 (2.34 to 4.97$)$ & $<0.001$ & 1 & 2.59 (1.76 to 3.82$)$ & $<0.001$ \\
\hline Model 3 & 1 & 3.44 (2.32 to 5.09$)$ & $<0.001$ & 1 & 2.54 (1.71 to 3.76$)$ & $<0.001$ \\
\hline \multicolumn{7}{|l|}{$\beta$-cell dysfunction } \\
\hline Cases, n (\%) & $199(24.8)$ & $28(16.4)$ & & $186(23.3)$ & $41(23.6)$ & \\
\hline \multicolumn{7}{|l|}{ OR $(95 \% \mathrm{Cl})$} \\
\hline Model 1 & 1 & $0.63(0.40$ to 0.98$)$ & 0.039 & 1 & 0.89 (0.59 to 1.32$)$ & 0.55 \\
\hline
\end{tabular}

Model 1 adjusted for children's sex, age, birth weight, and feeding status.

Model 2 adjusted for variables in model 1 plus children's screen time, sleep time, outside activity, daily energy intake, fiber, fat, protein and carbohydrate consumption.

Model 3 adjusted for variables in model 2 plus maternal delivery age, smoking status, education, gestational age at delivery, prepregnancy body mass index (BMI), weight gain during pregnancy, and hypertensive disorder of pregnancy.

HOMA- $\beta$ was used to estimate $\beta$-cell secretory function.

${ }^{*}$ Data were log transformed. Differences in fasting glucose, fasting insulin, HOMA-IR and HOMA- $\beta$ were calculated using general linear model, and adjusted for children's age, sex, birth weight, feeding status, screen-watching time, sleep time, outside activity, daily energy intake, fiber, fat, protein and carbohydrate consumption. Means \pm SEs were presented.

HOMA-IR, homeostatic model assessment of insulin resistance.

status, education, gestational age, HDP, pre-pregnancy BMI and gestational weight gain (model 3). All the statistical analyses were performed with SPSS statistics V.25.0 for Windows software package (IBM). Two-sided $\mathrm{p}<0.05$ was considered statistically significant.

\section{RESULTS}

There were differences in children's gender, age, birth weight, screen-watching time, daily energy intake, fasting plasma glucose and fasting insulin, and maternal prepregnancy BMI among children with different statuses of general and abdominal obesity (table 1).

General overweight/obese children had higher levels of fasting insulin, HOMA-IR and HOMA- $\beta$ compared with normal weight children (table 2). Only general overweight/ obese children $(4.43 \mathrm{mmol} / \mathrm{L}$ vs $4.35 \mathrm{mmol} / \mathrm{L}, \mathrm{p}=0.008)$ but not abdominal obesity individuals $(4.39 \mathrm{mmol} / \mathrm{L}$ vs $4.36 \mathrm{mmol} / \mathrm{L}, \mathrm{p}=0.28$ ) had higher levels of fasting glucose compared with normal weight children. Compared with normal weight children, general overweight/obese children had higher multivariable-adjusted (children's sex, age, birth weight, feeding status, outdoor physical activity time, screen time, sleep time, daily energy intake, daily fiber intake, energy from carbohydrate, protein, and fat-model 2) ORs for hyperglycemia (1.58, 95\% CI 1.09 to 2.30$)$ and insulin resistance (3.41, 95\% CI 2.34 to 4.97$)$, and lower OR for $\beta$-cell dysfunction $(0.63,95 \%$ CI 0.40 to 0.99$)$. After additional adjustment for maternal delivery age, smoking status, education, gestational age, HDP, pre-pregnancy $\mathrm{BMI}$ and gestational weight gain, the positive association of 
Table 3 Childhood major glucose metabolism outcomes according to joint status of general and abdominal obesity

\begin{tabular}{|c|c|c|c|c|c|}
\hline & Normal weight & & General overweig & oesity & \\
\hline & $\begin{array}{l}\text { Normal waist } \\
\text { circumstance }\end{array}$ & Abdominal obesity & $\begin{array}{l}\text { Normal waist } \\
\text { circumstance }\end{array}$ & Abdominal obesity & $P$ value \\
\hline Subjects, $n$ & 727 & 75 & 72 & 99 & \\
\hline Fasting glucose (mmol/L) & $4.35 \pm 0.01$ & $4.36 \pm 0.04$ & $4.45 \pm 0.04^{\star}$ & $4.43 \pm 0.04$ & 0.07 \\
\hline Fasting insulin (mIU/L) & $2.43 \pm 0.07$ & $2.54 \pm 0.22$ & $3.06 \pm 0.23^{*}$ & $4.26 \pm 0.20^{*} † \ddagger$ & $<0.001$ \\
\hline HOMA-IR§ & $-0.43 \pm 0.01$ & $-0.47 \pm 0.04$ & $-0.32 \pm 0.04^{*} \dagger$ & $-0.21 \pm 0.03^{\star} \dagger \ddagger$ & $<0.001$ \\
\hline HOMA- $\beta \S$ & $1.71 \pm 0.01$ & $1.70 \pm 0.04$ & $1.76 \pm 0.04$ & $1.87 \pm 0.04^{\star} \dagger \ddagger$ & $<0.001$ \\
\hline Hyperglycemia & & & & & \\
\hline Cases, n (\%) & $166(22.8)$ & $16(21.3)$ & $25(34.7)$ & $35(35.4)$ & \\
\hline OR $(95 \% \mathrm{Cl})$ & & & & & \\
\hline Model 1 & 1 & $0.96(0.53$ to 1.73$)$ & $1.68(0.99$ to 2.85$)$ & 1.77 (1.12 to 2.78$)$ & 0.005 \\
\hline Model 2 & 1 & $0.94(0.52$ to 1.72$)$ & 1.51 (0.88 to 2.60$)$ & $1.62(1.01$ to 2.60$)$ & 0.023 \\
\hline Model 3 & 1 & $0.96(0.52$ to 1.75$)$ & 1.52 (0.87 to 2.64$)$ & 1.58 (0.97 to 2.56$)$ & 0.035 \\
\hline Insulin resistance & & & & & \\
\hline Cases, n (\%) & $149(20.5)$ & $14(18.7)$ & $29(40.3)$ & $50(50.5)$ & \\
\hline OR $(95 \% \mathrm{Cl})$ & & & & & \\
\hline Model 1 & 1 & 1.29 (0.69 to 2.42$)$ & 2.51 (1.48 to 4.28$)$ & 5.03 (3.18 to 7.97$)$ & $<0.001$ \\
\hline Model 2 & 1 & 1.25 (0.66 to 2.36$)$ & 2.32 (1.35 to 3.99$)$ & 4.73 (2.94 to 7.62$)$ & $<0.001$ \\
\hline Model 3 & 1 & 1.27 (0.67 to 2.42$)$ & 2.41 (1.38 to 4.23$)$ & 4.61 (2.83 to 7.52$)$ & $<0.001$ \\
\hline$\beta$-cell dysfunction & & & & & \\
\hline Cases, n (\%) & $175(24.1)$ & 24 (32) & $11(15.3)$ & $17(17.2)$ & \\
\hline OR $(95 \% \mathrm{Cl})$ & & & & & \\
\hline Model 1 & 1 & 1.23 (0.72 to 2.08$)$ & $0.68(0.35$ to 1.35$)$ & 0.61 (0.35 to 1.08$)$ & 0.08 \\
\hline Model 2 & 1 & $1.16(0.67$ to 1.98$)$ & 0.72 (0.36 to 1.43$)$ & $0.60(0.34$ to 1.06$)$ & 0.07 \\
\hline Model 3 & 1 & $1.13(0.65$ to 1.95$)$ & 0.73 (0.36 to 1.47$)$ & 0.62 (0.35 to 1.12$)$ & 0.11 \\
\hline
\end{tabular}

Model 1 adjusted for children's sex, age, birth weight, and feeding status.

Model 2 adjusted for variables in model 1 plus children's screen time, sleep time, outside activity, daily energy intake, fiber, fat, protein and carbohydrate consumption.

Model 3 adjusted for variables in model 2 plus maternal delivery age, smoking status, education, gestational age at delivery, pre-pregnancy body mass index (BMI), weight gain during pregnancy, and hypertensive disorder of pregnancy.

HOMA- $\beta$ was used to estimate $\beta$-cell secretory function.

${ }^{*} \mathrm{P}<0.05$ compared with normal weight and normal waist circumstance group.

$+\mathrm{P}<0.05$ compared with abdominal obesity only group.

$\ddagger \mathrm{P}<0.05$ compared with general overweight/obesity only group.

§Data were log transformed. Differences in fasting glucose, HOMA-IR and HOMA- $\beta$ were calculated using general linear model, and adjusted for children's age, sex, birth weight, feeding status, screen-watching time, sleep time, outside activity, daily energy intake, fiber, fat, protein and carbohydrate consumption. Means \pm SEs were presented.

HOMA-IR, homeostatic model assessment of insulin resistance.

general overweight with the risks of hyperglycemia (1.56, $95 \%$ CI 1.06 to 2.30$)$ and insulin resistance $(3.44,95 \% \mathrm{CI}$ 2.32 to 5.09$)$ was still significant, but the inverse association between general overweight and $\beta$-cell dysfunction became marginally significant. Abdominal obesity children had increased insulin resistance $(2.54,95 \%$ CI 1.71 to 3.76 ; multivariable-adjusted model 3) but not hyperglycemia and $\beta$-cell dysfunction compared with normal waist circumstance children.

In the joint analyses, children with general overweight only or with both general and abdominal obesity but not with abdominal obesity only had higher levels of fasting insulin, HOMA-IR and HOMA- $\beta$ compared with normal weight children (table 3 ). The multivariable-adjusted ORs among normal weight children, abdominal obesity children only, general overweight/obese children only, and both general overweight/obese and abdominal obesity children were $1.00,0.96$ (95\% CI 0.52 to 1.75 ), $1.52(95 \%$ CI 0.87 to 2.64 ), and 1.58 (95\% CI 0.97 to 2.56) for hyperglycemia ( $\mathrm{p}$ for trend=0.035), 1.00, 1.27 (95\% CI 0.67 to 2.42 ), 2.41 (95\% CI 1.38 to 4.23 ), and 4.61 (95\% CI 2.83 to 7.52 ) for insulin resistance ( $\mathrm{p}$ for trend $<0.001)$, and $1.00,1.13(95 \%$ CI 0.65 to 1.95$), 0.73$ (95\% CI 0.36 to 1.47 ) and 0.62 (95\% CI 0.35 to 1.12 ) for $\beta$-cell dysfunction ( $\mathrm{p}$ for trend $=0.11$ ), respectively.

\section{DISCUSSION}

The present study indicated that both general obesity and abdominal obesity were associated with insulin 
resistance among children of mothers with GDM. Presence of either general obesity or combined general and abdominal obesity was positively associated with hyperglycemia and insulin resistance, but inversely associated with $\beta$-cell dysfunction among children of mothers with GDM.

Obesity is a powerful predictor for insulin resistance and diabetes in adults as well as in children and adolescents. ${ }^{21-23}$ However, it remained disputable about which kind of obesity, general or abdominal obesity, was more closely associated with glucose metabolism. Some researchers argued that both general and abdominal obesity strongly predicted type 2 diabetes. ${ }^{24}{ }^{25}$ Other researchers pointed out that abdominal obesity was more strongly associated with diabetes than general obesity. ${ }^{25-27}$ In China, both overall and central obesity were associated with diabetes in Chinese adults, ${ }^{28} 29$ and abdominal obesity was more closely associated with diabetes than general obesity assessed by BMI. ${ }^{30}$ Thus, it has been hypothesized that Asian adults have higher adiposity per unit BMI compared with other racial/ethnic groups, leading to an increased risk of type 2 diabetes at a lower BMI. ${ }^{31}$ However, it remained unknown whether general obesity was more closely associated with glucose metabolism than abdominal obesity in children. The present study indicated that both general and central obesity were indicators of childhood insulin resistance, and general obesity but not central obesity alone was positively associated with hyperglycemia among children with GDM mothers. Joint general and abdominal obesity implied the highest risk for hyperglycemia and insulin resistance.

The mechanism of the association between obesity and abnormal glucose metabolism is complicated. First, some studies pointed out that genetic predisposition to central obesity is associated with higher type 2 diabetes risk. ${ }^{32}$ Insulin resistance that developed in early-stage childhood obesity was correlated with higher expression of central obesity and type 2 diabetes-associated genes. ${ }^{33}$ These findings may in part explain the close relationship of central obesity with insulin resistance and type 2 diabetes. Second, obesity is a state of chronic inflammation. Inflammatory adipokines (eg, progranulin, procalcitonin, interleukin-34) were increased in obese children and associated with insulin resistance. ${ }^{34-36}$ Third, malnutrition is very common in obese individuals. Compared with non-obese children, obese children had lower levels of total 25-hydroxy vitamin D, vitamins A, $\mathrm{C}$ and $\mathrm{E}$, zinc and magnesium. Such malnutrition was associated with enhanced systemic inflammation and reduced insulin sensitivity in children. ${ }^{37-39}$ Additionally, excessive branched-chain amino acids and metabolite in obesity facilitated vascular fatty acid transport and caused insulin resistance. ${ }^{40}{ }^{41}$ Reduced blood supply in both subcutaneous and visceral fats, as well as resting skeletal muscle defect in glucose uptake has also been reported to increase insulin resistance in obesity. ${ }^{42}$

There are some advantages in this study. Our study enrolled a large number of children of mothers with GDM, and is the first report of the different association of general and abdominal obesity with major glucose metabolism in China. Further, a variety of confounding variables, such as the parameters of mothers before and during pregnancy and indices of the children including birth weight and lifestyle factors, were collected and used in the final analysis. There are some limitations in our study. First, this was a cross-sectional study, and the extrapolation of conclusions should be cautious. Second, the underlying mechanisms of the different association have not been investigated in the present study. More pathophysiologic studies are warranted in our future work.

In conclusion, both general obesity and abdominal obesity were associated with insulin resistance among children of mothers with GDM. Presence of either general obesity or combined general and abdominal obesity was positively associated with hyperglycemia and inversely associated with $\beta$-cell dysfunction. Our findings suggest that weight management should be given to children with either general or abdominal obesity.

\section{Author affiliations}

${ }^{1}$ Department of Endocrinology and Metabolism, Fengxian Hospital Affiliated to Southern Medical University, Shanghai Jiao Tong University Affiliated Sixth People's Hospital South Campus, Shanghai University of Medicine and Health Sciences Affiliated Shanghai Sixth People's Hospital South Campus, Shanghai, China ${ }^{2}$ Chronic Disease Epidemiology, Pennington Biomedical Research Center, Baton Rouge, Louisiana, USA

${ }^{3}$ Department of Mathematics, Shanghai Business School-Fengpu Campus, Shanghai, China

${ }^{4}$ Tianjin Health and Family Planning Commission, Tianjin, China

${ }^{5}$ Columbia University Mailman School of Public Health, New York, New York, USA ${ }^{6}$ Department of Preventive Medicine, Northwestern University Feinberg School of Medicine, Chicago, Illinois, USA

Contributors JLu, YG and GH conceptualized and designed the study, performed statistical analyses, interpreted the results, and drafted, reviewed and revised the manuscript. LW, WL, SZ, HL, JLe, JLi and SW collected the data and revised the manuscript. $A A B$ and $L H$ critically revised the manuscript for important intellectual content. All authors critically reviewed the scientific content and approved the final manuscript. GH is the guarantor of this work, and has full access to all the data in the study and takes responsibility for the integrity of the data and the accuracy of the data analysis.

Funding This study was supported by the European Foundation for the Study of Diabetes (EFSD)/Chinese Diabetes Society (CDS)/Lilly Program for Collaborative Research between China and Europe. GH was partly supported by grant from the National Institute of Diabetes and Digestive and Kidney Diseases (R01DK100790) and the National Institute of General Medical Sciences (U54GM104940) of the National Institutes of Health. JLu was supported by Shanghai key specialty construction projects (ZK2019B23).

Disclaimer The sponsors had no role in the preparation or approval of the manuscript.

Competing interests None declared.

Ethics approval This study was approved by the Human Subjects Committee of Tianjin Women's and Children's Health Center.

Provenance and peer review Not commissioned; externally peer reviewed.

Data availability statement Data are available upon reasonable request. Data are available upon the permission of the corresponding author $\mathrm{GH}$.

Open access This is an open access article distributed in accordance with the Creative Commons Attribution Non Commercial (CC BY-NC 4.0) license, which permits others to distribute, remix, adapt, build upon this work non-commercially, and license their derivative works on different terms, provided the original work is properly cited, appropriate credit is given, any changes made indicated, and the use is non-commercial. See: http://creativecommons.org/licenses/by-nc/4.0/. 
ORCID iDs

Junhong Leng http://orcid.org/0000-0002-6742-0830

Gang Hu http://orcid.org/0000-0002-6172-8017

\section{REFERENCES}

1 Afshin A, Forouzanfar MH, Reitsma MB, et al. Health effects of overweight and obesity in 195 countries over 25 years. N Engl J Med 2017;377:13-27.

2 Zhou Y, Zhang Q, Wang T, et al. Prevalence of overweight and obesity in Chinese children and adolescents from 2015. Ann Hum Biol 2017;44:642-3

3 Zhang J, Li X, Hawley N, et al. Trends in the prevalence of overweight and obesity among Chinese school-age children and adolescents from 2010 to 2015. Child Obes 2018;14:182-8.

4 World Health Organization. Childhood overweight and obesity. Geneva, Switzerland: World Health Organization, 2016. http://www. who.int/dietphysicalactivity/childhood/en/

5 Kelsey MM, Zaepfel A, Bjornstad P, et al. Age-Related consequences of childhood obesity. Gerontology 2014;60:222-8.

6 Li S, Chen W, Srinivasan SR, et al. Relation of childhood obesity/ cardiometabolic phenotypes to adult cardiometabolic profile: the Bogalusa heart study. Am J Epidemiol 2012;176 Suppl 7:S142-9.

7 Nightingale CM, Rudnicka AR, Owen CG, et al. Influence of adiposity on insulin resistance and glycemia markers among U.K. children of South Asian, black African-Caribbean, and white European origin: child heart and health study in England. Diabetes Care 2013;36:1712-9.

8 Sinha R, Fisch G, Teague B, et al. Prevalence of impaired glucose tolerance among children and adolescents with marked obesity. $N$ Engl J Med 2002;346:802-10.

9 Kindler JM, Lobene AJ, Vogel KA, et al. Adiposity, insulin resistance, and bone mass in children and adolescents. J Clin Endocrinol Metab 2019;104:892-9.

10 Tam WH, Ma RCW, Yang X, et al. Glucose intolerance and cardiometabolic risk in adolescents exposed to maternal gestational diabetes: a 15-year follow-up study. Diabetes Care 2010;33:1382-4.

11 Tam WH, Ma RCW, Ozaki R, et al. In utero exposure to maternal hyperglycemia increases childhood cardiometabolic risk in offspring. Diabetes Care 2017;40:679-86.

12 Zhang F, Dong L, Zhang CP, et al. Increasing prevalence of gestational diabetes mellitus in Chinese women from 1999 to 2008. Diabet Med 2011;28:652-7.

13 Consultation WHO. Definition, diagnosis and classification of diabetes mellitus and its complications. Part 1: diagnosis and classification of diabetes mellitus. Geneva: World Health Organisation, 1999.

14 Li W, Zhang S, Liu H, et al. Different associations of diabetes with $\beta$-cell dysfunction and insulin resistance among obese and nonobese Chinese women with prior gestational diabetes mellitus. Diabetes Care 2014;37:2533-9.

15 Qiao Y, Zhang T, Liu H, et al. Joint association of birth weight and physical activity/sedentary behavior with obesity in children ages 9-11 years from 12 countries. Obesity 2017;25:1091-7.

16 Li Y-ping, He Y-na, Zhai F-ying, et al. [Comparison of assessment of food intakes by using 3 dietary survey methods]. Zhonghua Yu Fang Yi Xue Za Zhi 2006;40:273-80.

17 Zhang S, Liu H, Zhang C, et al. Maternal glucose during pregnancy and after delivery in women with gestational diabetes mellitus on overweight status of their children. Biomed Res Int 2015;2015:543038

$18 \mathrm{Lu}$ J, Hou X, Zhang L, et al. Associations between clinical characteristics and chronic complications in latent autoimmune diabetes in adults and type 2 diabetes. Diabetes Metab Res Rev 2015;31:411-20.

19 Zhou Z, Xiang Y, Ji L, et al. Frequency, immunogenetics, and clinical characteristics of latent autoimmune diabetes in China (LADA China study): a nationwide, multicenter, clinic-based cross-sectional study. Diabetes 2013;62:543-50.
20 Fryar CD, Gu Q, Ogden CL. Anthropometric reference data for children and adults: United States, 2007-2010. Vital Health Stat 11 2012;252:1-48.

21 Skinner AC, Perrin EM, Moss LA, et al. Cardiometabolic risks and severity of obesity in children and young adults. $N$ Engl J Med 2015;373:1307-17

22 Weiss R, Dziura J, Burgert TS, et al. Obesity and the metabolic syndrome in children and adolescents. N Engl J Med 2004;350:2362-74.

23 Romualdo MCdosS, Nóbrega FJde, Escrivão MAMS. Insulin resistance in obese children and adolescents. J Pediatr 2014;90:600-7.

24 Wang Y, Rimm EB, Stampfer MJ, et al. Comparison of abdomina adiposity and overall obesity in predicting risk of type 2 diabetes among men. Am J Clin Nutr 2005;81:555-63.

25 Taylor AE, Ebrahim S, Ben-Shlomo Y, et al. Comparison of the associations of body mass index and measures of central adiposity and fat mass with coronary heart disease, diabetes, and all-cause mortality: a study using data from 4 UK cohorts. Am J Clin Nutr 2010;91:547-56.

26 Frank LK, Heraclides A, Danquah I, et al. Measures of general and central obesity and risk of type 2 diabetes in a Ghanaian population. Trop Med Int Health 2013;18:141-51.

27 Siren R, Eriksson JG, Vanhanen H. Waist circumference a good indicator of future risk for type 2 diabetes and cardiovascular disease. BMC Public Health 2012;12:631.

$28 \mathrm{Xu} \mathrm{Y,} \mathrm{Wang} \mathrm{L,} \mathrm{He} \mathrm{J,} \mathrm{et} \mathrm{al.} \mathrm{Prevalence} \mathrm{and} \mathrm{control} \mathrm{of} \mathrm{diabetes} \mathrm{in}$ Chinese adults. JAMA 2013;310:948-59.

29 Yang W, Lu J, Weng J, et al. Prevalence of diabetes among men and women in China. N Engl J Med 2010;362:1090-101.

30 Wang L, Liu H, Zhang S, et al. Obesity index and the risk of diabetes among Chinese women with prior gestational diabetes. Diabet Med 2014;31:1368-77.

31 Weng J-P, Hu G. Diabetes: Leveraging the tipping point of the diabetes pandemic. Diabetes 2017;66:1461-3.

32 Huang T, Qi Q, Zheng Y, et al. Genetic predisposition to central obesity and risk of type 2 diabetes: two independent cohort studies. Diabetes Care 2015;38:1306-11.

33 Skoczen S, Wojcik M, Fijorek K, et al. Expression of the centra obesity and type 2 diabetes mellitus genes is associated with insulin resistance in young obese children. Exp Clin Endocrinol Diabetes 2015;123:252-9.

34 Alissa EM, Sutaih RH, Kamfar HZ, et al. Serum progranulin levels in relation to insulin resistance in childhood obesity. $J$ Pediatr Endocrinol Metab 2017:30:1251-6.

35 Chang E-J, Lee SK, Song YS, et al. II-34 is associated with obesity, chronic inflammation, and insulin resistance. J Clin Endocrinol Metab 2014;99:E1263-71.

36 Abbasi A, Corpeleijn E, Postmus D, et al. Plasma procalcitonin is associated with obesity, insulin resistance, and the metabolic syndrome. J Clin Endocrinol Metab 2010;95:E26-31.

37 Miraglia del Giudice E, Grandone A, Cirillo G, et al. Bioavailable vitamin D in obese children: the role of insulin resistance. J Clin Endocrinol Metab 2015;100:3949-55.

38 García OP, Ronquillo D, del Carmen Caamaño M, et al. Zinc, iron and vitamins $A, C$ and $E$ are associated with obesity, inflammation, lipid profile and insulin resistance in Mexican school-aged children Nutrients 2013;5:5012-30.

39 Celik N, Andiran N, Yilmaz AE. The relationship between serum magnesium levels with childhood obesity and insulin resistance: a review of the literature J Pediatr Endocrinol Metab 2011;24:675-8.

40 Jang C, Oh SF, Wada S, et al. A branched-chain amino acid metabolite drives vascular fatty acid transport and causes insulin resistance. Nat Med 2016;22:421-6.

41 Newbern D, Gumus Balikcioglu P, Balikcioglu M, et al. Sex differences in biomarkers associated with insulin resistance in obese adolescents: metabolomic profiling and principal components analysis. J Clin Endocrinol Metab 2014;99:4730-9.

42 Ferrannini E, lozzo P, Virtanen KA, et al. Adipose tissue and skeletal muscle insulin-mediated glucose uptake in insulin resistance: role of blood flow and diabetes. Am J Clin Nutr 2018;108:749-58. 